[Radiocarbon, Vol. 8, 1966, P. 534-540]

\title{
ON THE RELATIONSHIP BETWEEN RADIOCARBON DATES AND TRUE SAMPLE AGES
}

\section{MINZE STUIVER}

Radiocarbon Laboratory, Yale University, New Haven, Connecticut

\author{
HANS E. SUESS \\ University of California, San Diego, La Jolla, California
}

The result of a radiocarbon determination is commonly expressed as an age given in radiocarbon years. An error is usually assigned to each value as a measure of the statistical uncertainty of the measurement. Date lists published in this journal use a standard form of reporting dates and their errors (see Editorial Statements in Radiocarbon, v. 3 and v. 4). The conversion of a radiocarbon age, given in radiocarbon years B.P. (i.e., radiocarbon years elapsed since the origin of the sample) to a true calendar year makes necessary certain assumptions with respect to: (1) the half-life of $\mathrm{C}^{14}$, (2) the production rate of $\mathrm{C}^{14}$ by cosmic rays, (3) the size of reservoirs into which $\mathrm{C}^{14}$ is distributed and the exchange rate of this distribution. Libby $(1955$, p. 10$)$ has shown that as an approximation one may assume that reservoir size and production and distribution rates, and therefore the $\mathrm{C}^{14}$ activity in atmospheric $\mathrm{CO}_{2}$ have been constant. However, the more accurate measurements of recent years have shown that at least one of these quantities must have varied with time. This means that a more complicated relationship exists between radiocarbon age and exact calendar age of a sample than had been assumed by Libby. This relationship cannot be determined theoretically, but can be derived empirically by determination of the radiocarbon contents of samples of known age. The following summarizes our present knowledge regarding differences between radiocarbon ages and true ages and the present status of the empirical calibration of the radiocarbon time scale.

Fluctuations of the $\mathrm{C}^{14}$ activity of the atmospheric $\mathrm{CO}_{2}$ with time can be expected on various theoretical grounds. A change in $\mathrm{CO}_{2}$ content of the atmosphere or a change in the mixing rate of the ocean could lead to a perturbation of the atmospheric $\mathrm{C}^{14}$ inventory. It has been pointed out by Libby (1963) and Wood and Libby (1964) that these changes have to be either improbably large or of long duration in order to affect the specific $\mathrm{C}^{14}$ activity in the biosphere to a measurable degree. Because of the long average lifetime of $\mathrm{C}^{14}$ (ca. $8000 \mathrm{yr}$ ), the $\mathrm{C}^{14}$ inventory responds to such changes extremely slowly, i.e., on a time scale of thousands of years. However, because of a delay of some $10 \mathrm{yr}$ in the $\mathrm{CO}_{2}$ exchange between atmosphere and ocean (Revelle and Suess, 1957), and because of the slow mixing of surface water into deeper layers of the ocean (Bien, Rakestraw and Suess, 1963; Suess, 1954), the response of atmospheric $\mathrm{C}^{14}$ to such changes is faster than that of the whole $\mathrm{C}^{14}$ inventory on the Earth's surface. There are no observations that would indicate that a change of the required magnitude (of the order of 30 
percent) has taken place in the $\mathrm{CO}_{2}$ concentration in the atmosphere or in the mixing properties of the oceans. We know, however, that the production rate of $\mathrm{C}^{14}$ by cosmic rays undergoes large variations because of a modulation of the galactic cosmic ray flux by the sun. According to Lingenfelter (1963), this change in $\mathrm{C}^{1+}$ production rate is approx. 30 percent during an 11-year cycle. J. A. Simpson, University of Chicago (pers. commun.) believes that such change can at times reach perhaps a factor of 2.

De Vries (1958) was the first who noticed discrepancies between radiocarbon and calendar ages of wood known to date from ca. A.D. 1700 and A.D. 1500. De Vries suspected a correlation with climatic events, in particular for the period often called the "little ice age." Independently, one of us (Stuiver, 1961) has pointed out that the available $\mathrm{C}^{14}$ data from wood of known age indicate a correlation between $\mathrm{C}^{14}$ inventory and solar activity. The more recent measurements by Stuiver (1965) for the 18th and 19th centuries, as well as by Suess (1965) for the second millennium A.D. confirm the correlation and show it to be the one predicted by cosmic ray observations.

Although historical records make it possible to retrace the magnitude of solar activity and sunspot numbers to the time of Christ (Schove, 1955), quantitative records of sunspot numbers date back to the 17 th century only. Variations of $\mathrm{C}^{14}$ activity can be determined as far back as rood is available that can be precisely dated by tree-ring studies. According to C. W. Ferguson of the Arizona Tree-Ring Laboratory (pers. commun.), bristlecone pine wood more than $6000 \mathrm{yr}$ old will soon be available for $\mathrm{C}^{1+}$ measurements. So far, the oldest reliable data are for wood from Sequoia gigantea and for historically dated wood from Egyptian tombs from the second millenium в.c. The $\mathrm{C}^{14}$ measurements indicate that the solar-induced changes of a few percent in $\mathrm{C}^{14}$ activity are superimposed upon larger changes on a longer time scale. This appears to be true in particular for the last two or three millenia B.c., when the specific $\mathrm{C}^{14}$ activity of the biosphere appeared to decrease steadily by ca. 0.4 percent per century (Suess, 1960; Damon and others, 1966).

The cause for the long-term variation of the $\mathrm{C}^{14}$ level is not known. The variation is certainly partially the result of a change in the cosmic ray production rate of radiocarbon, but climatic conditions that affect ocean mixing or atmospheric $\mathrm{CO}_{2}$ may contribute to its magnitude. The change in $\mathrm{C}^{11}$ production rate and in climate may well have a common cause in the activity of the sun (Suess, 1966). The cosmic-ray flux, and hence the production rate of $\mathrm{C}^{14}$, is a function not only of the solar activity but also of the magnetic dipole moment of the Earth (Elsasser and others, 1963; Kigoshi and Hasegawa, 1966). There are indications that this dipole moment has changed over the past $6000 \mathrm{yr}$, but the extrapolation of single measurements to total earth dipole moments make quantitative correlations unreliable. 
In any case it is presently impossible to determine on theoretical ground, what the relationship is between a radiocarbon date and the true age of a sample. However, the work of tree-ring laboratories promises to make available precisely dated samples many thousand years old so that it will be possible to establish an empirical correction table relating radiocarbon ages to the true ages of the sample. Establishment of such an empirical correlation table will require an enormous amount of work involving at least six precision measurements per century as far back as tree-ring dated wood is available. So far, sufficient measurements have been made only for the second millennium A.D.., and for the prior time approximate corrections can be but suggested. In general, radiocarbon dates since A.D. 1000 are too young; one of the larger deviations is around A.D. 1700 when radiocarbon ages erroneously suggest 19th century material. Radiocarbon dates from the first millennium A.D. are generally 50 to $100 \mathrm{yr}$ too old. However, there may be a fine structure in this trend. Samples from the 7 th century A.D., for example, may not require such a correction. For the period before 250 B.c. radiocarbon ages are too young again, the correction being roughly proportional to the calendar year B.c.

Conditions during glacial times may have been considerably different. An evaluation of all the factors indicates a possibility that the $\mathrm{C}^{14}$ inventory differed from the present by as much as 20 to 30 percent. This would introduce an error of 2000 to $2500 \mathrm{yr}$ for samples from glacial times (Suess, 1960, 1966). Such an error for many Pleistocene samples will not greatly affect conclusions based upon $\mathrm{C}^{14}$ measurements.

Radiocarbon data given in the literature are calculated with the so-called conventional Libby half-life of $5568 \mathrm{yr}$. The average of the most recent measurements gives the more accurate value of $5730 \pm 30$ yr (Mann and others, 1961; Olsson and others, 1962, 1963). An increase of 2.9 percent for all the $\mathrm{C}^{14}$ ages quoted in the literature would, therefore, give a better approximation to the true age than the values currently listed. The difference, however, is negligible and unimportant compared with the above-mentioned corrections necessary for converting radiocarbon years into calendar years. This is one reason that it was decided at the Pullman Radiocarbon Conference, June 1965, that the conventional Libby half-life of 5568 yr should be retained for calculating radiocarbon dates.

The possibility of establishing correction tables for the conversion of conventional radiocarbon dates to true age depends on whether or not the variations in the $\mathrm{C}^{14}$ activity of the atmosphere and biosphere are world-wide phenomena. A comparison of samples from different geographical areas indicates that this is indeed the case, although there are indications of small variations with geographical latitude. Vogel (1965), who compared samples from North America, Europe, and the southern hemisphere, lists differences of the order of 5 per mil (corresponding to a $40 \mathrm{yr}$ radiocarbon "age" difference). In North America 
the differences seem to be less than 5 per mil (Stuiver, 1965). We can therefore consider variations in atmospheric $\mathrm{C}^{14}$ to be world-wide phenomena.

The data obtained so far from samples of known age permit calibration of the radiocarbon time scale for the last $1000 \mathrm{yr}$. Table 1, which gives the conversion of true ages to radiocarbon ages and vice versa, is based on measurements at La Jolla (Suess, 1965) and, for the period A.D. 1700-1800, on measurements of the Yale Radiocarbon Laboratory (Stuiver, 1965).

The laboratory standard in general use for the determination of radiocarbon ages is oxalic acid, supplied by the Bureau of Standards. Ninety-five percent of the activity of the oxalic acid corresponds by international agreement with the natural $\mathrm{C}^{14}$ activity of wood grown in A.D. 1950, after correction for isotopic fractionation and for industrial (fossil) $\mathrm{CO}_{2}$ in the atmosphere. The original La Jolla radiocarbon clata were derived by comparison with wood from a fir tree grown in Oregon between 1870 and 1880, while the Yale measurements were made with oxalic acid as the standard. The La Jolla results have been converted

\section{TABLE 1}

Radiocarbon ages and true ages for the last $2000 \mathrm{yr}$. The radiocarbon ages are based on a half life of $5568 \mathrm{yr}$; the standard year of reference is A.D. 1950. For each calendar year only one radiocarbon age exists, whereas a radiocarbon age may correspond to more than one true age.

\begin{tabular}{ccc|ccc}
\hline $\begin{array}{c}\text { Calendar } \\
\text { Year }\end{array}$ & $\begin{array}{c}\text { True } \\
\text { Age }\end{array}$ & $\begin{array}{c}\text { Radiocarbon } \\
\text { Age }\end{array}$ & $\begin{array}{c}\text { Calendar } \\
\text { Year }\end{array}$ & $\begin{array}{c}\text { True } \\
\text { Age }\end{array}$ & $\begin{array}{c}\text { Radiocarbon } \\
\text { Age }\end{array}$ \\
\hline A.D. 1800 & 150 & 130 & A.D. 1320 & 630 & 610 \\
1780 & 170 & 150 & 1300 & 650 & 650 \\
1760 & 190 & 100 & 1280 & 670 & 690 \\
1740 & 210 & 130 & 1260 & 690 & 710 \\
1720 & 230 & 100 & 1240 & 710 & 710 \\
1700 & 250 & 80 & 1220 & 730 & 730 \\
1680 & 270 & 120 & 1200 & 750 & 920 \\
1660 & 290 & 170 & 1180 & 770 & 910 \\
1640 & 310 & 280 & 1160 & 790 & 890 \\
1620 & 330 & 330 & 1140 & 810 & 880 \\
1600 & 350 & 340 & 1120 & 830 & 900 \\
1580 & 370 & 320 & 1100 & 850 & 920 \\
1560 & 390 & 270 & 1080 & 870 & 930 \\
1540 & 410 & 250 & 1060 & 890 & 950 \\
1520 & 430 & 280 & 1040 & 910 & 970 \\
1500 & 450 & 330 & 1020 & 930 & 990 \\
1480 & 470 & 370 & 1000 & 950 & 1000 \\
1460 & 490 & 420 & 250 B.C. to A.1). 1000; radiocarbon \\
1440 & 510 & 470 & ages are generally ca. 50 to 100 \\
1420 & 530 & 490 & older than true ages, but deriations \\
1400 & 550 & 550 & from this rule are possible. \\
1380 & 570 & 580 & & & \\
1360 & 590 & 600 & & & \\
1340 & 610 & 610 & & & \\
\hline
\end{tabular}


to the oxalic acid standard by comparing the results of 16 tree-ring measurements of the 18th and 19th centuries with similar tree-ring measurements at Yale. The resulting correction to the La Jolla measurements amounts to only 3.6 per mil in $\mathrm{C}^{14}$ activity, corresponding to 30 radiocarbon yr. The error introduced by the change of reference standard is small and probably does not exceed 20 yr. The statistical variations in the actual measurements are largely removed by the smoothing, necessary to graduate the data, but they leave a residual uncertainty in the calibrated data of ca. $\pm 30 \mathrm{yr}$. However, the existence of short-term oscillations may introduce an additional uncertainty of the same order of magnitude.

Although for each calendar year there is only one radiocarbon age, the reverse is not true. This is illustrated in Fig. 1; in some instances a series of true ages exists for one radiocarbon age. This is especially true for the last $500 \mathrm{yr}$. The figure representing the relation between radiocarbon ages and true ages is a slight modification of the figure published by Suess (1965, p. 5950); the main difference is inclusion of the correction for the La Jolla reference standard.

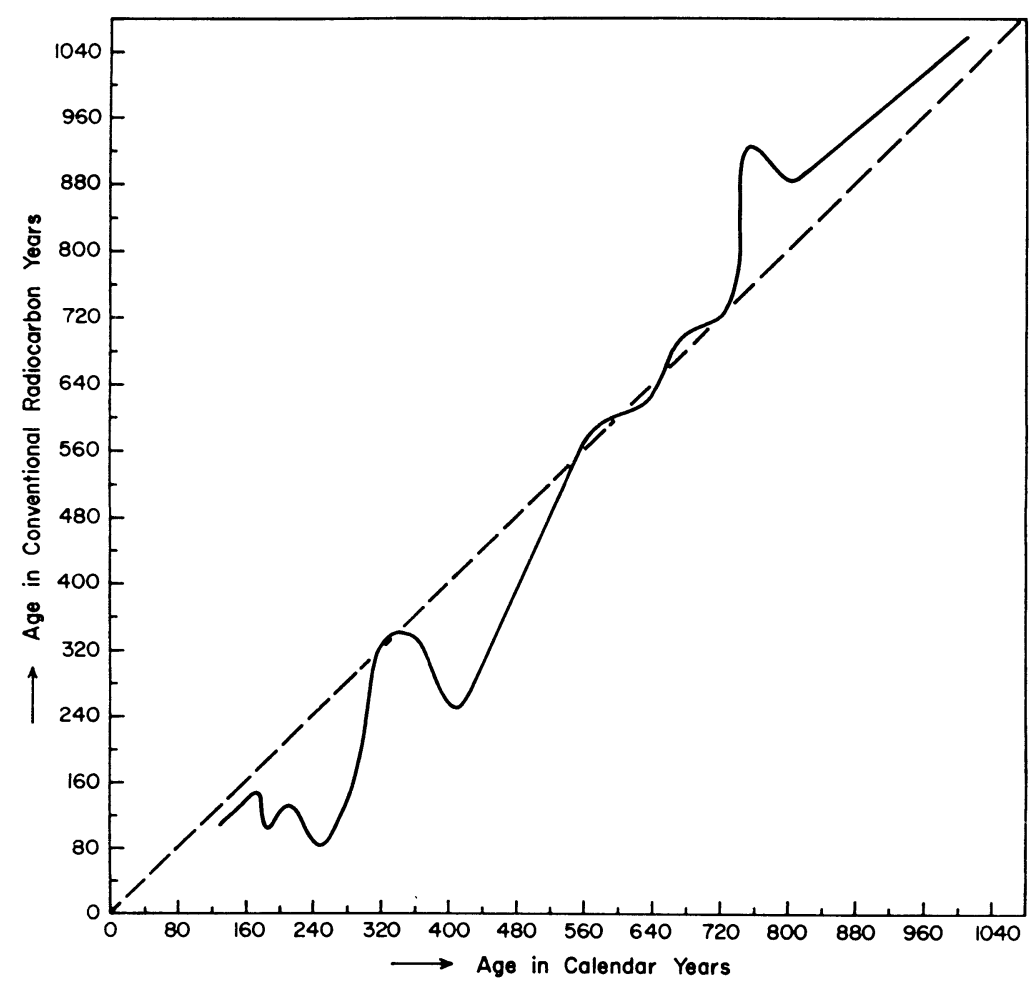

Fig. 1. The relation between radiocarbon ages and true ages for the last millenium. 
Work is now in progress to extend the calibration of the radiocarbon time scale back to the time before Christ, as far as dendrochronologically dated wood samples are available. The analyses of treerings and of historically dated Egyptian samples carried out so far indicate a decreasing $\mathrm{C}^{14}$ activity for the time from ca. 4000 B.c. to ca. 200 B.c. Therefore, the discrepancy between true ages and radiocarbon ages for this period is rapidly increasing with increasing age. A radiocarbon age of $4000 \mathrm{yr}$, for example, corresponds to a true age more than $500 \mathrm{yr}$ greater. As a crude approximation the true age $T$ can be estimated from the radiocarbon age $R$ by using the equation

$$
\mathrm{T}=1.4 \mathrm{R}-1100 .
$$

Superimposed upon the trend of this type, however, are fluctuations of the type observed during the past $1000 \mathrm{yr}$, as shown in Fig. 1. It therefore appears premature to attempt corrections of radiocarbon ages for B.c. times as long as the accurate calibration data have not been determined.

The ultimate refinement of the radiocarbon dating method by applying empirical corrections still leaves well-known possibilities of errors through admixture of older carbon in lacustrine materials or through contamination of the sample with foreign carbon such as that of humic acid, roots, and other substances present in soils. Other errors may arise from effects of the local $\mathrm{C}^{14}$ environment in dense forests and near the ground, due to bacterial decomposition of soil components (Keeling, 1961). Also, uptake of carbonate ions through the roots of the growing plants can lead to small differences of the order of a few per mil of $\mathrm{C}^{14}$ (equivalent to age differences of the order of $10 \mathrm{yr}$ ), although the uptake of carbon by the roots of trees has been found to be negligible.*

* Radiocarbon measurements by the Yale and La Jolla laboratories are financially supported through N.S.F. Grants GP 4879 and GP 2022, respectively.

\section{REFERENCES}

Bien, G., Rakestraw, N. W., and Suess, H. E., 1963, Radiocarbon dating of the decp water of the Pacific and Indian Ocean: Radioactive Dating, Athens, Grecce, Symp. 159-173, IAEA, Vienna, Proc.; Bull. Inst. Ocean., Monaco, v. 61.

Damon, P. E., Long, A., and Grey, D. C., 1966, Fluctuation of atmospheric carbon-14 during the last six millenia: Jour. Geophys. Research, v. 71, p. 1055-1064.

De Vries, Hl., 1958, Variations in concentration of radiocarbon with time and location on earth: Koninkl. Ned. Akad. Wetensch. Prodc. B61, p. 94-102.

Elsasser, W. E., Ney, P., and Winckler, J. R., 1956, Cosmic-ray intensity and geomagnetism: Nature, v. 178, p. 1226-1227.

Hughes, E. E., and Mann, W. B., 1964, The half-life of carbon-14: comments on massspectroscopic method: Internat. Jour. Appl. Rad. Iso., v. 15, p. 97-100.

Karlén, I., Olsson, I. U., Kallberg, P., and Kilicci, S., 1964, Absolute determination of the activity of two $\mathrm{C}^{14}$ dating standards: Arkiv för Geofysik, v. 4, p. 465-471.

Keeling, C. D., 1958, The concentration and isotopic abundances of atmospheric carbon dioxide in rural areas: Geochim. et Cosmochim. Acta, v. 13, p. 322-334.

1961, The concentration and isotopic abundances of carbon dioxide in rural and marine air: Geochim et Cosmochim. Acta, v. 24, p. 277-298.

Kigoshi, K. and Hasegawa, H., 1965, Secular variations of atmospheric radiocarbon concentration and its dependence on geomagnetism: Jour. Geophys. Research, v. 71, , p. $1065-1072$. 
Libby, W. F., 1955, Radiocarbon Dating: Chicago, University of Chicago Press. 1963, Accuracy of radiocarbon dates: Science, v. 140, p. 278.

Lingenfelter, R. E., 1963, Production of carbon-14 by cosmic-ray neutrons: Revs. Geophysics, v. 1, p. 1.

Mann, W. B., Marlow, W. F., and Hughes, E. E., 1961, The half-life of carbon-14: Jour. Appl. Rad. Iso., v. 11, p. 57-67.

Olsson, I. U., Karlén, I., Turnbull, A. H., and Prosser, N. J. D., 1962, A determination of the half-life of $\mathrm{C}^{14}$ with a proportional counter: Arkiv för Fysik, v. 22, p. 237-255.

Olsson, I. U., Karlén, I., 1963, The half-life of $\mathrm{C}^{14}$ and the problems which are encountered on absolute measurements on beta-decaying gases: Radioactive Dating, IAEA, Vienna.

Revelle, R., and Suess, H. E., 1957, Carbon dioxide exchange between atmosphere and ocean: Tellus, v. 9, p. 18.

Schove, D. J., 1955, The sunspot cycle 649 B.C. to 2000 A.D.: Jour. Geophys. Res., v. 60 , p. $126-145$.

Stuiver, M., 1961, Variations in radiocarbon concentration and sunspot activity: Jour. Geophys. Res., v. 66, p. 273-276.

1965, Carbon-14 content of 18 th and 19th century wood: variations correlated with sunspot activity: Science, v. 149, p. 533-535.

Suess, H. E., 1954, Natural radiocarbon and the rate of exchange of carbon dioxide between the atmosphere and the sea: Williams Bay Conf. September 1953, Proc., NAS-NSF Pub., p. 52.

1960, Secular changes in the concentration of atmospheric radiocarbon: Conf. on Problems Related to Interplanetary Matter, Highland Park, Illinois, Proc., Nuclear Science Series Report No. 33, NAS-NRC, Washington, D. C., Pub. 845 , p. 90.

- 1965, Secular variations in the cosmic-ray-produced carbon-14 in the atmosphere and their interpretations: Jour. Geophys. Res., v. 70, p. 5937-5951. 1966, Climatic changes, solar activity, and the cosmic ray production rate of radiocarbon: Meteorological Monographs, in press.

Vogel, J. C., 1965, Carbon-14 content of wood from different locations: Internat. $\mathrm{C}^{14}$ and $\mathrm{H}^{3}$ Conf., Pullman, Washington, Proc.

Wood, L. and Libby, W. F., 1964, Geophysical implications of radiocarbon date discrepancies: Isotopic and Cosmic Chemistry, Craig, Miller and Wasserberg, eds., North-Holland Pub. Co., Amsterdam, p. 205-210. 